\title{
Fonksiyonel Nörolojik Semptom Bozukluğunda Bilişsel Dauranışçı Tedavinin Bilişsel Hatalar Üzerine Etkisi
}

The Effect of Cognitive Behavioral Therapy on Cognitive Errors in Functional Neurological Symptom Disorder Mehmet Hamdi Örüm ${ }^{1}$ i

\section{özeT}

AMAÇ: Çalışmanın amacı fonksiyonel nörolojik semptom bozukluğu (FNSD) tanılı hastalarda farmakoterapi (FT) ve FT ile bilişsel davranışçı tedavi (BDT) kombinasyonunun bilişsel hatalar üzerine etkisini karşılaştırmaktır.

GEREÇ VE YÖNTEM: Bu ileriye yönelik çalışmada FNSD tanısı Ruhsal Bozuklukların Tanısal ve Sayımsal El Kitabı'nın beşinci versiyonuna (DSM-5) göre konuldu ve ardışık olgular başvuru sırasına göre rastgele seçildi. Alt tipler klinik ve somatoform disosiasyon ölçeği (SDÖ)'nin birlikte değerlendirilmesiyle belirlendi. Bilişsel hatalar düşünce özellikleri ölçeği (DÖÖ) ile, hastanın genel durumu global değerlendirme ölçeği (GAS) ile değerlendirildi.

BULGULAR: FT grubu 37 hastadan, FT+BDT grubu 20 hastadan oluşuyordu. Gruplar arasında ortalama yaş ( $p=0,312)$, ortalama eğitim süresi $(p=0,345)$ açısından anlamlı farklılık saptanmadı. Tedavi öncesinde, DÖÖ’nün kişilerarası ilişkiler alt ölçeği (DÖÖ-ıP) ( $p=0,085)$, DÖÖ’nün bireysel başarı alt ölçeği (DÖÖ-PA) $(p=0,145), S D O ̈ ~(p=0,132)$ ve GAS $(p=0,421)$ açısından gruplar arasında anlamlı farklılık saptanmadı. Hem FT $(p=0,011)$, hem de $F T+B D T(p<0,001)$ grubunda DÖÖ-IP açısından tedavi öncesi ve sonrası değerler açısından anlamlı farklıık ortaya çıktı. DÖÖ-PA açııından FT grubundan tedavi öncesi ve sonrası arasında anlamlı farklılı saptanmazken ( $p=0,101)$; $F T+B D T$ grubunda anlamlı farklılık saptandı $(p=0,048)$. Tedavi sonrası değerlere göre, gruplar arasında GAS $(p=0,001)$ ve DÖÖ-IP $(p<0,001)$ açısından anlamlı farklılık ortaya çıktı.

SONUÇ: Bu çalışma, BDT'nin kişilerarası ilişkilerle (IP) ilişkili bilişsel hataları azalttığını göstermesi açısından önemlidir. Bu anlamlı değişiklik kişisel başarı (PA) ile ilişkili bilişsel hatalarda saptanmadı. BDT'nin ilaç tedavisiyle kombinasyonu bilişsel hataları azaltmada daha etkili olabilir.

Anahtar Kelimeler: fonksiyonel nörolojik semptom bozukluğu, konversiyon bozukluğu, bilişsel davranışçı tedavi, ilaç tedavisi

\section{ABSTRACT}

OBJECTIVE: Aim of this study is to compare the effects of pharmacotherapy (PT) and the combination of PT and cognitive behavioral therapy (CBT) on cognitive errors in patients diagnosed with functional neurological symptom disorder (FNSD).

MATERIALS AND METHODS: In this prospective study, the diagnosis of FNSD was made according to fifth edition of Diagnostic and Statistical Manual of Mental Disorders (DSM-5) and consecutive cases were randomly selected according to the order of admission. Subtypes were determined by evaluating the clinical and somatoform dissociation questionnaire (SDO) together. Cognitive errors were evaluated with the cognitive distortions scale (CDS), and the general condition of the patient was evaluated with the global assessment scale (GAS).

RESULTS: The PT group consisted of 37 patients, and the PT+CBT group consisted of 20 patients. There was no significant difference between the groups in terms of mean age $(p=0.312)$ and mean duration of education $(p=0.345)$. Before the treatment, there was no significant difference between the groups in terms of interpersonal relationship sub-scale of CDS (CDS-IP) ( $p=0.085)$, personal achievement sub-scale of CDS (CDS-PA) $(p=0.145), S D Q(p=0.132)$ and GAS $(p=0.421)$. Significant differences were found in both PT $(p=0.011)$ and $P T+C B T(p<0.001)$ groups in terms of CDS-IP values before and after treatment. While there was no significant difference between PT group before and after treatment in terms of CDS-PA ( $p=0.101)$, there was a significant difference in the $P T+C B T$ group $(p=0.048)$. According to the post-treatment values, there was a significant difference between the groups in terms of GAS $(p=0.001)$ and CDS-IP $(p<0.001)$.

CONCLUSION: This study is important as it shows that CBT reduces cognitive errors associated with interpersonal relationships (IP). This significant change was not detected in cognitive errors associated with personal achievement (PA). Combination of CBT with drug therapy may be more effective in reducing cognitive errors.

Keywords: functional neurological symptom disorder, conversion disorder, cognitive behavioral therapy, drug therapy

Yazışma Adresi/Address for Correspondence: Mehmet Hamdi Örüm, MD, Psikiyatri Kliniği, Kahta Devlet Hastanesi 02100 Adıyaman/Türkiye 


\section{GiRiş}

Fonksiyonel nörolojik semptom bozukluğu (FNSD), eski adıyla konversiyon bozukluğu, nörolojik yada başka tıbbi bir hastalıkla açıklanamayan sinir sistemi belirtilerini ifade eder (1). Bununla birlikte belirtiler gerçektir ve ciddi işlevsellik kaybına neden olurlar. FNSD, psikojenik epileptik olmayan nöbet (PNES), somatosensöriyel belirtiler, motor belirtiler ya da bunların kombinasyonları şeklinde ortaya çıkabilir (2). Anormal yürüyüş, güçsüzlük, paraliziler, ataksi ve afoni en sık rastlanan motor FNSD (M-FNSD) belirtileridir (3). PNES de epilepsi ile en sık karışan nöbetlerdendir (4). FNSD’nin etiyolojisi aydınlatılamamıştır. Durum, nörolojik bir bozukluk, fiziksel ya da psikolojik bir travmaya bağı olarak tetiklenebilir. Tedavi edilmeyen FNSD, ciddi duygusal stres, depresyon ve anksiyete belirtilerine yol açar; sosyal ve başarı alanlarında sorunlara neden olur (5).

Fizik muayene, laboratuvar ve görüntüleme bulguları sonucunda FNSD düşünülen hastalarda tedavi planı yapılır. Kişide acil bir psikiyatrik durum olmadığı için genel olarak ayaktan tedavi önerilir. Acil servis koşullarında bu hastaların tedavilerinin gerçekleştirilmesi mümkün değildir. Hasta stabil hale getirildikten sonra taburcu edilmeleri ve psikiyatri hekimine psikiyatrik muayeneye uygun oldukları zaman yani konuşarak kendilerini anlatabildikleri dönemde getirilmeleri uygundur (6). Tedavi amacıyla ilaçlar ve psikoterapi yalnız başına ya da kombine olarak uygulanabilir (7). Kronik ve zor olgularda tedavide hastanın engellenme yaşadığı sorunların çözümü ve sorunlar karşısında konversiyon tepkisi yerine daha gelişmiş ve işlevsel tepkiler geliştirmesinin sağlanması amaçlanır. Tedavi başarısını etkileyen unsurlar gerektiğinde tanının gözden geçirilmesini, hastanın sürekli eğitimini ve bilgilendirilmesini, gerekli durumlarda yardımcı sağıı personelinin katılımını, komorbid tıbbi, nörolojik ve psikiyatrik durumların erken dönemde tedavi edilmesini içerir $(6,7)$.

FNSD’nin ilaçla tedavisi genellikle seçici serotonin geri alım inhibitörleri (SSGi) ve düşük doz antipsikotik (AP) yapılır. Psikoterapinin, çoğu hastada yararlı olduğu bildirilmiştir (5). Bilişsel baş etme becerilerinin geliştirilmesi, bilişsel davranışçı aile müdahaleleri, işlevsel davranışların pekiştirilmesi, ikincil kazancın engellenmesi ve gevşeme egzersizleri gibi bilişsel davranışçı terapi (BDT) yöntemlerinin tedavideki önemi büyüktür (8). Bununla birlikte, FNSD'de herhangi bir tedavinin kesin etkinliğini destekleyen bir kanıt yoktur. FNSD'nin tedavi yöntemlerinin yararını ortaya çıkarmaya yönelik çalışmalar yapıımış ve bu yöntemler kendi aralarında ve kontrol gruplarıla karşılaştırılmıştır. FNSD'nin BDT ile ya da BDT ve farmakoterapi kombinasyonuyla tedavisinin bilişsel süreçler üzerine olumlu etkisi olduğu gösterilmiştir (7). Bilindiği gibi, FNSD hastaları sağ|ıkı kontrollere göre daha yüksek bilişsel hata düzeyine sahiptir (9). FNSD hastalarındaki bu bilişsel hataların, tedavi ile azaldığına dair bilgiler bulunmakla birlikte, tedavi yöntemlerinin bu olumlu gidiş üzerine etkisi yeterince araştırılmamıştır. Ayrıca bilişsel hatalar kişilerarası ilişkiler (IP) ve kişisel başarı (PA) alanları diye ayrı ayrı daha önce değerlendirilmemiştir. Bu çalışmadaki amacımız bir sıcak biliş ölçeği olan ve IP ve PA alanlarındaki bilişsel hataları ayrı ayrı değerlendiren Düşünce Özellikleri Ölçeği (DÖÖ)'nün FNSD tedavileriyle ilişkisi araştırmaktır. Hipotezimiz, BDT uygulamasının FNSD alt tiplerindeki bilişsel hata düzeyinin azaltılmasına etkisinin farklı olduğu yönündedir.

\section{GEREÇ VE YÖNTEM}

\section{Çalışma Deseni}

$\mathrm{Bu}$ ileriye yönelik çalışma, bir ilçe devlet hastanesinin psikiyatri polikliniğinde gerçekleştirildi. Polikliniğe yapılan ardışık başvurular içinden randomize olarak kadın olguların dâhil edildiği bu çalışmada Ruhsal Bozuklukların Tanısal ve Sayımsal El kitabı'nın beşinci versiyonu (DSM-5) (10)'e göre FNSD tanısı almış kişiler, belirtilerine ve uygulanacak tedavi yöntemlerine göre iki gruba ayırıldı: M-FNSD ve PNES. Alt tipler belirlenirken, hastanın kliniğinin Somatoform Dissosiasyon Ölçeği (SDÖ) ile uyumlu olmasına bakıldı. Görüşmeler psikiyatrik muayeneye uygun bir ortamda gerçekleştirildi. Çalışma 01/02/2020-01/09/2020 tarihleri arasında gerçekleştirildi. Çalışma Helsinki Bildirgesi'ne uygun olarak yürütüldü ve protokol Adıyaman Üniversitesi Girişimsel Olmayan Klinik Araştırmalar Etik Kurulu tarafından onaylandı (Proje Tanımlama Kodu: 2020/1-26).

\section{İçleme ve Dışlama Kriterleri}

Çalışmaya katılmayı kabul eden ve DSM-5'e göre FNSD'nin PNES ya da M-FNSD alt tiplerinden olan hastalar çalışmaya dâhil edildi. Klinik ile SDÖ yanıtları uyumsuz olan 18 kişi çalışma dışı bırakıldı. Zekâ geriliği olan ve tiroit, karaciğer ve böbrek hastalıkları gibi ruhsal durumlarını doğrudan veya dolaylı olarak etkileyebilecek organik rahatsızlıkları olan hasta ve kontroller çalışmaya dâhil edilmedi. Bu şekilde, ek psikiyatrik ya da organik hastalı̆̆ olan ve ilaç kullanan 35 kişi çalışmadan dışlandı. Görüşmeler sırasında eksik bilgi 
veren hastalar çalışmaya alınmadı. Çalışmanın herhangi bir aşamasında çalışma gerekliliklerinden herhangi birini gerçekleştirmeyen hastalar çalışmadan dışlandı. Bu şekilde çalışmanın farklı aşamalarında toplamda 13 kişi çalışma dışı bırakıldı.

\section{Sosyodemografik Veri Formu}

Araştırmacı tarafından sosyodemografik ve klinik bilgileri içeren bir form dolduruldu. Ankette değişkenler olarak yaş, cinsiyet, eğitim düzeyi, medeni durum, çalışma durumu ve aile psikiyatrik öyküsü kullanıldı.

\section{Somatoform Disosiasyon Ölçeği}

SDÖ, somatoform disosiasyon ciddiyetini değerlendiren 20 maddelik bir öz bildirim aracıdır. Nijenhuis ve ark. tarafından geliştirilmiştir (11). Ölçeğin Türkçe versiyonun 1 aylık test-tekrar test korelasyonu 0.95 'tir. Bir Türk klinik örneğinde kesme noktası 35 için 0,84 duyarlılık ve 0,87 özgüllük sağlamıştır (12).

\section{Düşünce Özellikleri Ölçeği (Cognitive Distortions Scale)}

Özdel ve ark. tarafından 2014 yılında Türkçeye çevrilmiş her bir bölümünde 10 madde olan, iki ayrı bölümden oluşan 20 maddelik bir ölçektir (13). On farklı maddede on farklı düşünce tarzı (zihin okuma, felaketleştirme, hep ya da hiç tarzı düşünme, duygudan sonuç çıkarma, etiketleme, zihinsel filtreleme, aşırı genelleme, kişiselleştirme, -meli malı ifadeleri, olumluyu küçültme ya da yok sayma) bulunmaktadır. Öncelikle her düşünce tarzının ne olduğu açıklanmaktadır. Daha sonra her bir düşünce tarzının daha iyi anlaşııması amacıyla iki örnek durum anlatılır. Anlatılan bu iki durumdan bir tanesi sosyal ilişkilerle (IP, arkadaş, eş ve aile gibi) diğeri ise kişisel başarılarla ilgilidir (PA, bir sınavı geçmek ya da işte başarısız olmak gibi). Bu kurgu örneklerinin amacı her bir düşünce tarzının gerçek hayatta nasıl olabileceğini ölçeği dolduran kişinin anlamasını kolaylaştırmaktır. Ölçeği dolduran kişinin başta bu tanımlanan düşünüş tarzını anlaması ve bu düşünüş tarzını ne sıklıkta kullandığını 1 (asla)'den 7 (her zaman)'ye kadar olan likert tarzı puanlamaya yansıtması istenmektedir. Klinik ve klinik olmayan örneklemden elde edilen sonuçlara göre ölçeğin Cronbach alfa değeri klinik olgular için 0.933, klinik olmayan olgular için 0.918 bulunmuştur.

\section{Global Değerlendirme Ölçeği (GAS)}

GAS, kısa sürede uygulanan ve psikopatolojideki değişikliklerin tüm yönlerini (psikolojik, sosyal ve mesleki işlevsellik) kapsayan bir derecelendirme ölçeğidir. Endicott tarafından 1976'da geliştirilmiştir ve 0-100 arasında puanlanır (14).

\section{Çalışma Protokolü ve Değerlendirme}

Yukarıda bahsedilen kriterlere uyan FNSD hastalarının onayları doğrultusunda farmakoterapi (FT) ve FT ile BDT kombinasyonu (FT+BDT) ile yönetilecek hastalar çalışmanın tek araştırmacısı tarafından iki gruba ayırıldı. FT grubu 43 hastadan oluşuyordu ve bu hastaların 23'sı M-FNSD, 20'si PNES alt tipine sahipti. FT+BDT grubu 27 hastadan oluşuyordu ve bu hastaların 14'ü PNES, 13'ü M-FNSD alt tipindendi. FT grubundan 6 kişi (4 PNES hastası ve $2 \mathrm{M}$ FNSD hastası) çalışmayı tamamlamadı. FT+BDT grubundan 7 kişi (4 PNES hastası ve 3 M-FNSD hastası) çalışmayı tamamlamadı. Çalışmanın sonunda, FT grubu 37 hastadan (16 PNES hastası ve 21 M-FNSD hastası), FT+BDT grubu 20 hastadan (10 PNES hastası ve 10 M-FNSD hastası) oluşuyordu (Figür 1).

Tüm hastalarda SSGi tek başına ya da düşük doz AP (Haloperidol 1-2 mg/gün ya da olanzapin 2,5-5 mg/gün) ile kombine bir şekilde uygulandı. İlaç kullanımı bir aile üyesi tarafından teyit edildi. Tüm hastalar, 2 aylık bir süreç içerisinde 8 defa poliklinikte görüldü. Görüşme sıklığı 3-10 gün arasında değişiyordu ve onayları ile alınan iletişim numaralarından bu sürenin sınırlarına uyulması sağlanıyordu. FT grubunda görüşmeler destekleyici tarzdaydı ve şu şekilde gerçekleştiriliyordu: Iyilik halinin sorgulanması, yeni belirti ve bulguların değerlendirilmesi, ilaç yan etkilerinin sorgulanması, mevcut ilaç tedavisinin konuşulup düzenlenmesi ve öneriler. Literatürle uyumlu olarak bu protokol standart tıbbi bakım (STB) olarak nitelendirildi.

FT+BDT grubu, ilaç tedavisine ek olarak BDT uygulanan gruptu. Standart BDT seans yapısına uyuldu. Seans yapısı şu şekildeydi: Duygudurum kontrolü ve kısa güncelleme; bir önceki seansla bağlantı kurma; ödev kontrolü; gündem belirleme; gündem maddelerini ele alma; seans arası alıştırma (ev ödevi) verilmesi; seansın özetlenmesi; hastadan geribildirim alınması. Bununla birlikte, hasta profilinin nispeten düşük eğitimli bir kesimi kapsaması nedeniyle BDT uygulamasında çeşitli değişikliklere gidildi. BDT seans yapısı hasta ve terapistin ihtiyaçlarına uygun şekilde ve literatürle uyumlu olarak gerekli durumlarda esnetildi. Bu esneklik seans sayısı ve süresini içeriyordu (15, 16). 
Figür 1. Çalışma Akış Şeması

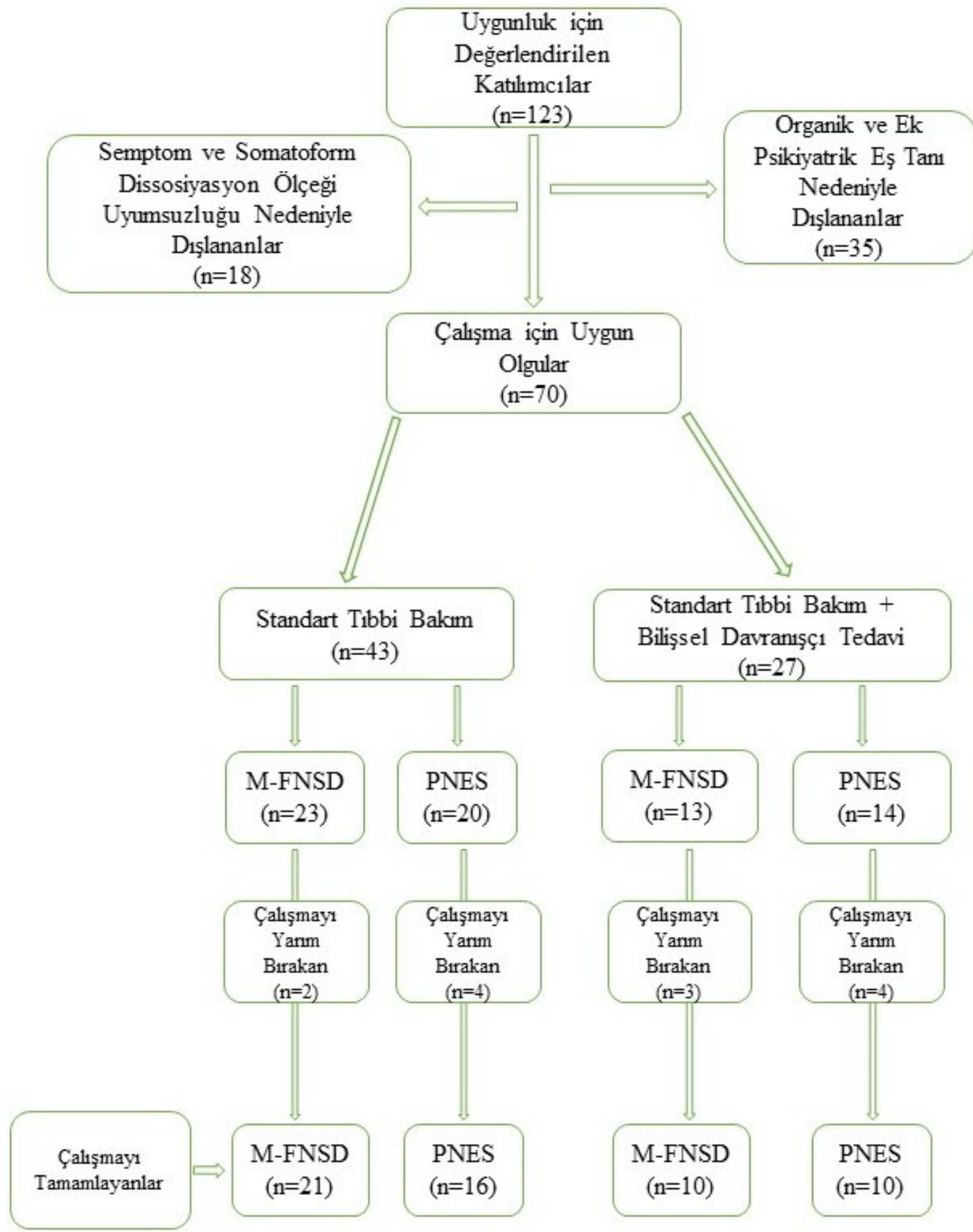

BDT süreci bireysel bazı esneklikler göstermekle birlikte genel olarak şu şekildeydi: [1] Seans süresi en fazla 55, en az 25 dakika olacak şekildeydi. [2] Değerlendirme görüşmesi 2 ayrı seanstan oluşuyordu. Değerlendirme görüşmesinde tanı belirlendi, sorun kavramlaştırıldı, tedavi motivasyonu değerlendirildi, bilişsel formülasyon yapıldı ve tedavi amaçları belirlendi. [3] iki değerlendirme görüşmesinden sonra BDT seansları başlatıldı. Gündem oluşturma rasyoneli anlatıldı; değerlendirme esnasında verilen ölçekler varsa bunlar konuşuldu ve geribildirim alındı; sorunlar tanımlandl; terapi amacı belirlendi ve beklentiler konuşuldu; danışana model anlatıldı; rahatsızlığının bilişsel modeliyle ilgili bilgi verildi; ev ödevi verildi; özetleme ve sonrasında geri bildirim ile seans sonlandırıldı. ABC modeli (duygu, düşünce ve davranış) tanıtıldı. Bilişsel ve davranışçı teknikler örneklerle anlatıldı. 
Tedavinin başında hem FT hem de FT + BDT grubuna SDÖ, DÖÖ ve GAS doldurtuldu. Sekiz haftalık sürecin sonunda GAS ve DÖÖ yeniden uygulandı.

\section{İstatistiksel Analiz}

İstatistiksel analizlerde Windows SPSS 22.0 programı (IBM Corp. Released 2013. IBM SPSS Statistics for Windows, Version 22.0. Armonk, NY: IBM Corp) kullanıldı. Tanımlayıcı istatistikler ve sürekli değişkenler ortalama \pm standart sapma, kategorik değişkenler ise frekans ve yüzde olarak verildi. Kategorik verilerin analizinde Ki-kare testi kullanıldı. Değişkenlerin dağılımını incelemek amacıyla KolmogorovSmirnov testi, sürekli bağımsız değişkenleri değerlendirmek için Mann-Whitney $U$ testi kullanıldı. Bağımlı grupların karşılaştırılmasında Wilcoxon testi kullanıldı. Istatistiksel anlamlıık düzeyi tüm değerler için $p<0.05$ olarak kabul edildi.

\section{BULGULAR}

FT grubu 37 hastadan (16 PNES [\%43,24] + 21 M-FNSD $[\% 56,76])$, FT+BDT grubu 20 hastadan (10 PNES [\%50,0] ve 10 M-FNSD $[\% 50,0])$ oluşuyordu. Gruplar arasında ortalama yaş $(p=0,312)$, ortalama eğitim süresi $(p=0,345)$, ailede psikiyatrik hastalık öyküsü $(p=0,443)$ ve FNSD alt tipleri $(p=0,124)$ açısından anlamlı farklılık saptanmadı.. FT grubunda ortalama hastalık başlangıç yaşı 22,32 $\pm 5,12$ yıldl; FT+BDT grubunda bu süre $23,89 \pm 5,74$ yıldı $(p=0,256)$. Hastaların hiçbirinde yatış öyküsü yoktu. DÖÖ-IP $(p=0,085)$, DÖÖ-PA $(p=0,145)$, SDÖ $(p=0,132)$ ve GAS $(p=0,421)$ açısından gruplar arasında anlamlı farklııı saptanmadı. Grupların sosyodemografik verilerinin, DÖÖ, SDÖ ve GAS değerlerinin karşılaştırılması Tablo 1 'de gösterildi.

Tablo 1. Grupların Sosyodemografik Verilerinin ve Tedavi Başlangıcındaki Ölçek Değerlerinin Karşılaştırılması

\begin{tabular}{|rccc|}
\hline Değişkenler & $\begin{array}{c}\text { FT }(\mathbf{n}=\mathbf{3 7}) \\
(\mathbf{O r t} \pm \text { SD) }\end{array}$ & $\begin{array}{c}\text { FT+BDT }(\mathbf{n = 2 0}) \\
\text { (Ort } \pm \text { SD) }\end{array}$ & $\mathbf{p}$ \\
Yaş (yıl) & $22,32 \pm 5,12$ & $23,89 \pm 5,74$ & 0,256 \\
Eğitim (yıl) & $8,45 \pm 3,12$ & $8,89 \pm 4,01$ & 0,345 \\
GAS & $68,97 \pm 11,21$ & $71,24 \pm 10,56$ & 0,421 \\
SDÖ & $43,25 \pm 17,53$ & $41,29 \pm 15,98$ & 0,132 \\
DÖÖ-IP & $52,54 \pm 8,35$ & $49,24 \pm 8,32$ & 0,085 \\
DÖÖ-PA & $30.54 \pm 4,42$ & $27,52 \pm 3.78$ & 0,145 \\
DÖÖ-T & $83,09 \pm 8,45$ & $76,76 \pm 8,01$ & 0,096 \\
\hline
\end{tabular}

${ }^{*} p<0,05$; Mann-Whitney $U$ testi ve Ki-kare testi kullanıldı. Ort $\pm S D$ : Ortalama artı eksi standart sapma, GAS: Global Değerlendirme Ölçeği, SDÖ: Somatoform Disosiasyon Ölçeği, DÖÖ-IP: Düşünce Özellikleri Ölçeği Kişilerarası iliş̧kiler Alt Ölçeği, DÖÖ-PA: Düşünce Özellikleri Ölçeği Bireysel başarı Alt Ölçeği, DÖÖ-T: Düşünce Özellikleri Ölçeği Total SkorU, FT: Farmakoterapi, BDT: Bilişsel Davranışçı Terapi, FT+BDT: Farmakoterapi ve Bilişsel Davranışçı Terapi,
BDT ve FT uygulaması sonrasında DÖÖ ve GAS hastalara yeniden uygulandı. Hem FT $(p=0,042)$, hem de FT+BDT $(p=0,002)$ grubunda GAS açısından tedavi öncesi ve sonrası değerler açısından anlamlı farklılık ortaya çıktı. Hem FT $(p=0,011)$, hem de FT+BDT $(p<0,001)$ grubunda DÖÖ-IP açısından tedavi öncesi ve sonrası değerler açısından anlamlı farklılık ortaya çıktı. Hem FT $(p=0,024)$, hem de FT+BDT ( $p=0,003)$ grubunda DÖÖ-T açısından tedavi öncesi ve sonrası değerler açısından anlamlı farklıık ortaya çıktı. DÖÖ-PA açısından FT grubundan tedavi öncesi ve sonrası arasında anlamlı farklılık saptanmazken $(p=0,101)$; FT+BDT grubunda anlamlı farklılık saptandı $(\mathrm{p}=0,048)$ (Tablo 2 ).

FT ve FT+BDT gruplarının tedavi sonrasındaki GAS ve DÖÖ değerleri karşılaştırıldı. Tedavi sonrası değerlere göre, gruplar arasında GAS $(p=0,001)$ ve DÖÖ-IP $(p<0,001)$ açısından anlamlı farklılık ortaya çıktı. Tedavi sonrası değerlere göre, gruplar arasında DÖÖ-PA $(p=0,125)$, DÖÖ-T $(p=0,077)$, açısından anlamlı farklılık ortaya çıkmadı.

Tablo 2. Sekiz Haftalık Tedavi Sonrasında FT $(n=37)$ ve FT+BDT ( $n=20)$ Gruplarının Ölçek Değerlerinin Karşılaştırılması

\begin{tabular}{|c|c|c|c|c|c|}
\hline & Gruplar & TÖ (OrtะSD) & $\mathrm{TS}(0 \mathrm{rt} \pm \mathrm{SD})$ & $p$ & Cohen's $d$ \\
\hline \multirow{2}{*}{ GAS } & FT & $68,97 \pm 11,21$ & $74,02 \pm 9,23$ & $0,042^{*}$ & 0,59 \\
\hline & $\mathrm{FT}+\mathrm{BDT}$ & $71,23 \pm 10,56$ & $85,56 \pm 8,85$ & $0,002^{*}$ & 1,26 \\
\hline \multirow{2}{*}{ DÖÖ-IP } & FT & $52,54 \pm 8,35$ & $46,24 \pm 8,63$ & $0,011^{*}$ & 0,83 \\
\hline & $\mathrm{FT}+\mathrm{BDT}$ & $49,25 \pm 8,32$ & $39,26 \pm 7,59$ & $<0,001^{*}$ & 2,01 \\
\hline \multirow{2}{*}{ DÖÖ-PA } & FT & $30.54 \pm 4,42$ & $28,45 \pm 4,01$ & 0,101 & 0,24 \\
\hline & $\mathrm{FT}+\mathrm{BDT}$ & $27,52 \pm 3.78$ & $24,75 \pm 3,99$ & $0,048^{*}$ & 0,52 \\
\hline \multirow{2}{*}{ DÖÖ-T } & FT & $83,09 \pm 8,45$ & $74,69 \pm 7,87$ & $0,024^{*}$ & 0,72 \\
\hline & $\mathrm{FT}+\mathrm{BDT}$ & $76,76 \pm 8,01$ & $65,01 \pm 7,55$ & $0,003^{*}$ & 1,18 \\
\hline
\end{tabular}

${ }^{*} p<0,05$; Wilcoxon testi kullanıldı. TÖ: Tedavi Öncesi, TS: Tedavi Sonrası, Ort $\pm S D$ : Ortalama artı eksi standart sapma, GAS: Global Değerlendirme Ölçeği, DÖÖ-IP: Düşünce Özellikleri Ö/çeği Kişilerarası iliş̧kiler Alt Ölçeği, DÖÖ-PA: Düşünce Özellikleri Ölçeği Bireysel başarı Alt Ölçeği, DÖÖ-T: Düşünce Özellikleri Ölçeği Total Skoru, FT: Farmakoterapi, BDT: Bilişsel Davranışçı Terapi, FT+BDT: Farmakoterapi ve Bilişsel Davranışçı Terapi

\section{TARTIŞMA}

FNSD tanılı hastalara sıklıkla depresif durumlar, anksiyete durumları, post travmatik stres bozukluğu ve hipokondriyazis eşlik eder (17). Kontrol gruplarının dâhil edilmediği bazı çalışmalar, antidepresan ve AP'lerin FNSD'de kullanılabileceğini bildirmiştir. Hangi ilacın daha uygun olacağı tam olarak bilinmemekle birlikte, komorbid psikiyatrik durumlara göre psikotropik ilaç seçimi yaygın bir uygulamadır. Komorbid psikiyatrik durumları tedavi etmek için ilaç tedavisine başlanmasının ne zaman uygun olacağ konusunda klinik kanaate güvenmek doğru bir yaklaşım olabilir (18). Psikoterapinin hastanın semptomlarına nasıl fayda sağlayacağı açıklanmalıdır. Poliklinik şartlarında 
hastaların büyük çoğunluğu $F T$, destekleyici görüşme ve hastalığın fizyolojik özelliklerinin açıklandığı ancak bilişsel süreçlerin yer almadığı bir STB süreci ile yönetilmektedir. Bizim çalışmamızda da FT kavramı STB kavramını ile aynı şeyi ifade etmesi amacıyla Goldstein ve ark.'ın çalışmasında anlatıldığı şekilde kullanılmıştır (16). FT'ye ek olarak BDT uygulanan grup ise STB ve BDT'nin birlikte uygulanışı şeklinde ifade edilebilir. Sonuç olarak STB uygulaması her iki grupta da bulunmaktadır.

Psikoterapi, beynin bilgiyi işleme şeklini değiştiren bir tedavi sürecine katkı sağlar. Bu sayede hastalar fiziksel semptomlar yoluyla sıkıntı ifade etme eğilimini en aza indirirler ve bu semptomlara yol açan işlevsiz inançların yerine daha uygun bir düşünce süreci getirilmiş olur (19). Bir psikoterapi ekolü olan BDT'nin de FNSD tedavisinde faydalı olduğu gösterilmiştir. BDT eğitimi, FNSD ve stres yanıt döngüsü ile ilişkili bilgiler içerir. Hastaları stres yönetimi teknikleri ve yeni davranışsal tepkiler konusunda eğitir. Bilişsel yapıda yer alan işlevsiz inançların değişmesine yardımcı olur (19). FNSD’nin ülkemizdeki sık karşıllaşılan tiplerinden biri olan PNES'de, BDT'nin etkililiği gösterilmiştir (20). Ayrıca standart ilaç tedavileriyle karşılaştırınca da BDT'nin anlamlı olarak daha etkili olduğu gösterilmiştir (7). LaFrance ve ark.'In PNES tanılı olgularda BDT'nin psikiyatrik belirti ve psikososyal değişkenler üzerine etkisini inceledikleri çalışmada 12 haftalık seanslara 38 denekten sadece 17'sinin devam ettiği; depresyon, anksiyete, somatik belirtiler, yaşam kalitesi ve psikososyal işlevsellik ölçeklerindeki ortalama puanların, başlangıçtan son seansa kadar iyileşme gösterdiği bildirilmiştir (21). LaFrance ve ark. SSGi kullanan PNES hastalarının BDT alan grupla karşılaştırılabileceğini bildirmiştir (21). Goldstein ve ark.'nin PNES olgularında BDT ile STB'nin etkisini karşılaştırdıkları çalışmada, nöbet sıklı̆̆ını azaltmada BDT'nin anlamlı olarak daha üstün olduğu görülmüştür (16). Aynı çalışmada her iki grubu da 33 denekten oluşturmuş ve STB grubunda çalışmayı tamamlayan 31 olgu olduğunu, BDT'ye ek olarak STB alan grupta ise 24 olgunun çalışmayı tamamladığını bildirmiştir. Mevcut antidepresan kullanımı olan olgular da çalışmaya dahil edilmiştir (16).

FNSD'deki bilişsel süreçleri ortaya çıkarmaya yönelik çalışmalar sayıca az ve kısıtıııkları fazla olan çalışmalardır. Bununla birlikte, FNSD'de de diğer birçok psikiyatrik bozuklukta olduğu gibi işlevsiz inançlar, tutum ve varsayımlar bulunmaktadır. Bu işlevsiz inançlar gelişim sürecinden kaynaklanmakta ve bilişsel hatalara yol açmaktadır. Bilişsel hatalar, bir olay hakkında anlık, planlanmamış olumsuz otomatik düşüncelere neden olur ve bu olumsuz yorumlar, psikolojik sorunların ortaya çıkmasında temel bir role sahiptir $(9,13)$. Bizim çalışmamızda, FT ve FT+BDT gruplarının FNSD alt tip hasta sayıları benzerdi. Bu şekilde tedavi başlangıcında hem kişilerarası ilişkiler hem de kişisel başarı alanlarındaki bilişsel hataları benzerdi. İki aylık tedavi sonunda her iki grupta da genel durum açısından anlamlı ve hasta lehine değişiklikler ortaya çıktı. Bu değişiklikler hastaların genel psikiyatrik durumunun ve işlevselliğinin değerlendirilmesini sağlayan GAS skorunda artışı ve bilişsel hata düzeyinde azalmayı içeriyordu. Kişilerarası ilişkileri yordayan DÖÖ-IP açısından her iki grupta da anlamlı değişiklikler saptandı. Ancak DÖÖ-PA açısından durum farklıydı. illaç tedavisine ek olarak BDT uygulanması kişisel başarı alanlarındaki bilişsel hataları azaltırken, sadece ilaç uygulaması belirgin değişiklik ortaya çıkarmadı. Tedavi sonrasındaki DÖÖ skorlarından IP gruplar arasında belirgin farklılık ortaya çıkarırken, PA açısından gruplar benzerdi. FNSD'deki bilişsel hata düzeyine, BDT veya diğer tedavi protokollerinin etkisi daha önce araştırılmamıştır. Bu nedenle literatürle bir karşılaştırma yapmak zorlaşmaktadır.

BDT'de amaçlardan biri bilişsel davranış değiştirmedir. Bilişsel davranış değiştirme yaklaşımı bireylerin kendi davranışlarını izleme ve yönetmede kendi kapasite ve tercihlerinin etkili olduğunu kabul eder. Bu yaklaşım, düşünceyi değiştirmenin duygu ve davranışı değiştirmedeki önemini vurgulamaktadır. İşte BDT'nin bu özelliği, FNSD gibi davranış değişikliğine ihtiyaç duyulan hastalıklarda ciddi bir başarı ortaya koymamızı sağlar (22). Bizim çalışmamızda da BDT uygulaması bilişsel hata düzeyinde azalma, hasta genel durumunda düzelmeyi sağladı.

\section{SONUÇ}

Bu çalışma, konversiyon bozukluğunda ilaç tedavisine ek olarak BDT uygulamasının kişilerarası ilişkilerle ilişkili bilişsel hataların anlamlı olarak azalttığını göstermesi açısından önemlidir. Çalışmamızın anlamlı bulgularına rağmen bazı kısıtlılıkları bulunmaktaydı. Hasta sayısının artırıldığı, hastaların daha uzun süre takip edildiği, ölçeklerin sayısının artırıldığı, alt tip sayısının artırılarak kendi aralarında karşılaştırmaların yapıldığı çalışmalara ihtiyaç duyulmaktadır. Çalışmanın gerçekleştirildiği hastanede FNSD tanılı erkek hasta sayısının kadın hasta sayısına göre 
belirgin olarak daha az olduğu gözlendiği ve bu nedenle kısıtlı sayıdaki erkek hastanın çalışmanın bulgularının yorumlanmasını zorlaştıracağı düşünüldüğü için erkek hastalar çalışmaya dâhil edilmemiştir. Ayrıca sosyodemografik değişkenlerin daha ayrıntılı işlenmesi konunun daha anlaşıır olmasını sağlayacaktır. Hastaların ilaç çeşidi ve dozlarının bilinmemesi bir diğer kısıtıııktır.

Etik: Bu çalışmanın etik kurulu alınmıştır (2020/1-26)

Ethics committee approval had been taken (2020/1-26).

Yazar katkı durumu; Çalışmanın konsepti; MHÖ dizaynı; MHÖ, Literatür taraması; MHÖ, verilerin toplanması ve işlenmesi; MHÖ, istatistik; MHÖ, yazım aşaması; MHÖ,

Author contribution status; The concept of the study; MHÖ, design; MHÖ, literature review; MHÖ, collecting and processing data; $\mathrm{MHÖ}$, statistics; $\mathrm{MHÖ}$, writing phase; $\mathrm{MHÖ}$,

Yazarlar arasında çıkar çatışması yoktur.

The author declares no conflict of interest.

Finansal Destek: yoktur / Funding: none

doi: https://doi.org/10.33713/egetbd.817732

Acknowledgements: The author would like to thank all of our patients who participated in the research.

Teşekkür: Araştırmaya katılan tüm hastalarımıza teşekkür ederiz.

\section{KAYNAKLAR}

1. Karadag AS, Kalenderoglu A, Orum $\mathrm{MH}$. Optical coherence tomography findings in conversion disorder: are there any differences in the etiopathogenesis of subtypes? Arch Clin Psychiatry. 2018;45(6):154-160. doi:10.1590/010160830000000179 .

2. Perez DL, Barsky AJ, Daffner K, Silbersweig DA. Motor and somatosensory conversion disorder: a functional unawareness syndrome? J Neuropsychiatry Clin Neurosci. 2012;24(2):141-151. doi:10.1176/appi.neuropsych.11050110.

3. Boeckle M, Liegl G, Jank R, Pieh C. Neural correlates of conversion disorder: overview and meta-analysis of neuroimaging studies on motor conversion disorder. BMC Psychiatry. 2016;16:195. doi:10.1186/s12888-016-0890-x.

4. Hingray C, Biberon J, El-Hage W, De Toffol B. Psychogenic non-epileptic seizures (PNES). Rev Neurol (Paris). 2016;172(45):263-269. doi:10.1016/j.neurol.2015.12.011.

5. Tsui $P$, Deptula A, Yuan DY. Conversion disorder, functional neurological symptom disorder, and chronic pain: comorbidity, assessment, and treatment. Curr Pain Headache Rep. 2017;21(6):29. doi:10.1007/s11916-017-0627-7.

6. Leary PM. Conversion disorder. Handb Clin Neurol. 2013;112:883-887. doi:10.1016/B978-0-444-52910-7.00010-6.

7. O'Neal MA, Baslet G. Treatment for patients with a functional neurological disorder (conversion disorder): an integrated approach. Am J Psychiatry. 2018;175(4):307-314. doi:10.1176/appi.ajp.2017.17040450.

8. Butler AC, Chapman JE, Forman EM, Beck AT. The empirical status of cognitive-behavioral therapy: a review of metaanalyses. Clin Psychol Rev. 2006;26(1):17-31. doi:10.1016/j.cpr.2005.07.003.

9. Kozlowska K, Palmer DM, Brown KJ, Scher S, Chudleigh C, Davies F, Williams LM. Conversion disorder in children and adolescents: a disorder of cognitive control. J Neuropsychol. 2015;9(1):87-108. doi:10.1111/jnp.12037.

10. American Psychiatric Association. (2013). Diagnostic And Statistical Manual of Mental Disorders, Fifth Edition (DSM-5). Arlington, VA: APP.

11. Nijenhuis ERS, Spinhoven $P$, Van Dyck R, Van Der Hart $O$, Vanderlinden $J$. the development and psychometric characteristics of the somatoform dissociation questionnaire (SDQ-20). J Nerv Ment Dis. 1996;184(11):688-694. doi:10.1097/00005053-199611000-00006.

12. Sar V, KundakçL, T, Kızıltan E, Bakim B, Bozkurt O. Differentiating dissociative disorders from other diagnostic groups through somatoform dissociation in Turkey. J Trauma Dissociation. 2000;1(4):67-80. doi:10.1300/J229v01n04_04.

13. Özdel K, Taymur I, Guriz SO, Tulaci RG, Kuru E, Turkcapar $\mathrm{MH}$. Measuring cognitive errors using the cognitive distortions scale (CDS): Psychometric properties in clinical and non-clinical samples. Plos ONE. 2014;9(8):E105956. doi:10.1371/journal.pone.0105956.

14. Endicott J, Spitzer RL, Psychiatric Rating Scales. In Comprehensive Textbook Of Psychiatry, 5th Ed.; Kaplan HI, Sadock BJ Eds.; Williams \& Wilkins: Baltimore, Maryland: 1989; Pp. 2391-2409.

15. Sensky T, Turkington D, Kingdon D, Scott JL, Scott J, Siddle R, O'Carroll M, Barnes TR. A randomized controlled trial of cognitive-behavioral therapy for persistent symptoms in schizophrenia resistant to medication. Arch Gen Psychiatry. 2000 Feb;57(2):165-72. doi: 10.1001/archpsyc.57.2.165. PMID: 10665619.

16. Goldstein LH, Chalder T, Chigwedere C, Khondoker MR, Moriarty J, Toone BK, Mellers JD. Cognitive-behavioral therapy for psychogenic nonepileptic seizures: a pilot RCT. Neurology. 2010 Jun 15;74(24):1986-94. doi: 10.1212/WNL.0b013e3181e39658.

17. Waller E, Scheidt CE. Somatoform disorders as disorders of affect regulation: A study comparing the tas-20 with non-selfreport measures of alexithymia. J Psychosom Res. 2004;57:239247. doi:10.1016/S0022-3999(03)00613-5.

18. Voon V, Lang AE. Antidepressant treatment outcomes of psychogenic movement disorder. J Clin Psychiatry. 2005;66:1529-1534. doi:10.4088/jcp.v66n1206.

19. Sharpe M, Walker J, Williams C, Stone J, Cavanagh J, Murray $G$, et al. Guided self-help for functional (psychogenic) symptoms: a randomized controlled efficacy trial. Neurology. 2011;77:564-572. doi:10.1212/WNL.0b013e318228c0c7.

20. Lafrance WC Jr, Baird GL, Barry JJ, Blum AS, Webb AF, Keitner 
$\mathrm{Gl}$, et al. Multicenter pilot treatment trial for psychogenic nonepileptic seizures: a randomized clinical trial. JAMA Psychiatry. 2014;71:997-1005.

doi:10.1001/jamapsychiatry.2014.817.

21. LaFrance WC Jr, Miller IW, Ryan CE, Blum AS, Solomon DA, Kelley JE, Keitner Gl. Cognitive behavioral therapy for psychogenic nonepileptic seizures. Epilepsy Behav. 2009 Apr;14(4):591-6. doi: 10.1016/j.yebeh.2009.02.016.

22. Rachman S. The evolution of behaviour therapy and cognitive behaviour therapy. Behav Res Ther. 2015;64:1-8. 